\title{
Meio século de mineração industrial na Amazônia e suas implicações para o desenvolvimento regional
}

\author{
MAURÍLIO DE ABREU MONTEIRO
}

\section{Introdução}

$\mathrm{Q}$ UANDO CHEGA ao fim a exploração industrial de algumas minas na Amazônia oriental brasileira, como a de manganês da Serra do Navio e de outras, menos expressivas, a exemplo das de ouro, também situadas no Amapá, toma-se ainda mais necessário examinar a história da mínero-metalurgia na região, refletindo acerca da relação entre tal atividade e o desenvolvimento regional, em especial porque os processos de extração e beneficiamento de minerais acalentaram, em amplos e diversos segmentos sociais, expectativas de rápida industrialização regional.

Além disso, as dinâmicas derivadas das atividades voltadas à extração e à transformação industrial de minerais incluem-se, seguramente, entre os mais expressivos elementos que contribuíram e contribuem para a efetivação de significativas mudanças na Amazônia oriental brasileira.

O liberalismo econômico dos anos de 1940

e o início da mineração industrial na Amazônia

O processo de valorização industrial de recursos minerais - entendida como a agregação de valor e conversão de recursos minerais em mercadoria - na Amazônia oriental brasileira iniciou-se com a exploração das reservas de minério de manganês da Serra do Navio, no então Território Federal do Amapá. Tal mina foi edificada em uma conjuntura marcada pelo estabelecimento, em termos nacionais, de um novo regime político e pela reorientação das relações estabelecidas entre o Estado e a economia. Era o fim da ditadura de Getúlio Vargas e a nova Constituição, promulgada em 1946, em substituição à Carta de 1937, estava fortemente inspirada em princípios do liberalismo econômico.

A Constituição de 1946 não deixou explícito, como ocorria na anterior, que os bens minerais eram uma propriedade da União. Nela, estipulou-se apenas que a exploração de tais recursos poderia ser conferida exclusivamente a brasileiros ou a sociedades organizadas no país. Rocha et al. (1987) lembram, entretanto, que não se estabeleceram quais seriam as restrições ou normas que limitariam a organização e a atuação de tais sociedades mineradoras.

Para a valorização da jazida estabeleceu-se concorrência, que foi vencida pela Indústria e Comércio de Minérios S. A. (Icomi), uma empresa brasileira de 
médio porte. Em 1947, ela recebeu autorização do Governo Federal para pesquisar e para explorar o manganês. Em 1950, sob a alegação da necessidade de aporte técnico, de recursos financeiros e diante da inexistência de óbices constitucionais, a Icomi associou-se à Bethlehem Steel, naquele período a segunda maior corporação norte-americana produtora de aço (Chandler, 1998, p. 360), sendo, em 1957, efetivado o primeiro embarque de minério, atividade que se estendeu por quatro décadas.

\section{Governos militares, interesses geopolíticos e mineração na Amazônia}

A valorização do minério de manganês da Serra do Navio permaneceu por aproximadamente duas décadas como a única extração mineral industrial significativa na Amazônia oriental brasileira. Quadro que vai se modificar significativamente, como decorrência das políticas desencadeadas pelo golpe militar de 1964. O estado autoritário, a partir da convergência da geopolítica com a doutrina de segurança nacional, formulou uma doutrina de intervenção interna, que tomou formas específicas no caso da Amazônia. Era imperioso "ocupar" a Amazônia, na visão dos principais segmentos dos governos militares (Oliveira, 1994, p. 86). Isto se buscou fazer por meio de políticas de desenvolvimento que pressupunham a firme articulação de interesses privados e o estabelecimento de uma ampla política de incentivos fiscais e creditícios, na qual se enquadravam as grandes empresas mínero-metalúrgicas.

\section{A criação do Programa de Pólos Agropecuários e Agrominerais da Amazônia}

Para agilizar a implantação de projetos exportadores, o Governo Federal criou, em 1974, o Programa de Pólos Agropecuários e Agrominerais da Amazônia - Polamazônia. Os planos federais previam a implantação de diversos "pólos de desenvolvimento na Amazônia brasileira", com destaque para a produção mineral. Ancoravam-se, portanto, numa visão de desenvolvimento regional que tinha por fundamento a necessidade de concentração espacial de capitais, capazes de produzir desequilíbrios, e, em decorrência destes, impulsionar processos de desenvolvimento por meio do surgimento de uma cadeia de ligações para frente e para trás das atividades produtivas consideradas "chave". Alguns dos pólos que integravam o Polamazônia eram Carajás, Trombetas e Amapá.

No "pólo do Amapá", a política de incentivos fiscais foi utilizada pela Icomi para implantar uma usina de pelotização, visando ao aproveitamento da parcela muito fina de minério de manganês. Naquele "pólo" também entrou em operação a primeira empresa dedicada à extração industrial de caulim na Amazônia. Tratava-se da Caulim da Amazônia (Cadam), criada como parte dos investimentos do milionário norte-americano Daniel Ludwig na área da Jari florestal.

Em 1977, a Cadam iniciou a lavra da mina de caulim situada na margem esquerda do rio Jari, atualmente município de Laranjal do Jari (AP). Daquele 
ano em diante, as instalações da empresa sofreram sucessivas ampliações e, atualmente, a mineradora possui uma capacidade instalada para valorizar até um milhão de $\mathrm{t} /$ ano de caulim.

\section{A explovação da bauxita da região do Trombetas}

Foi também naquele cenário dos anos de 1970 que se desenharam as condições que viabilizaram a extração e a comercialização da bauxita metalúrgica na Amazônia brasileira, mais especificamente as jazidas que haviam sido descobertas, ainda na década de 1960, às proximidades do rio Trombetas, no município paraense de Oriximiná, pela empresa canadense Aluminium Limited of Canada (Alcan).

Em 1972, a Alcan, alegando condições desfavoráveis ao produto no mercado mundial, paralisou o projeto. Na verdade, o que a empresa canadense fazia era barganhar o apoio do governo brasileiro, que, em consonância com aquela política de atração de capitais para a ocupação da região, escala a Companhia Vale do Rio Doce (CVRD) para representá-lo no negócio. Naquele momento (1975), a CVRD passou a ser a maior acionista da Mineração Rio do Norte (MRN), que passou a contar também com capital de outras empresas, além da Alcan, todas grandes consumidoras de bauxita. Em 1979, a MRN efetuou o seu primeiro embarque de bauxita para a Alcan, no Canadá. Daquela data em diante, a empresa vem ampliando a sua capacidade instalada, contando hoje com capacidade de lavra anual superior a dezesseis milhões de toneladas de bauxita.

Ações voltadas à industrialização regional na bauxita do Trombetas

A atuação do Governo Federal, tendo em vista a valorização das reservas de bauxita do Trombetas, não se limitou somente a viabilizar sua extração, mas também a implantação de estratégias para realizar a sua transformação em alumina e alumínio primário na própria região, para o que foi necessária a instalação de plantas químicas para a produção da alumina e a edificação de plantas metalúrgicas para a produção do alumínio. Estas últimas requeriam a disponibilidade de enorme quantidade de energia elétrica.

Para tanto, o Governo Federal promoveu negociações objetivando a formação de uma joint venture entre a CVRD e empresas japonesas para a produção de alumina e de alumínio, como também criou, em 1973, a Centrais Elétricas do Norte do Brasil S. A. (Eletronorte), com a finalidade de viabilizar a implantação da Usina Hidrelétrica de Tucurú, indispensável ao suprimento de energia para a transformação industrial da alumina em alumínio.

Consolidou-se em tais bases, em 1978, a Alumínio Brasileiro S. A. (Albras), joint venture criada como associação entre a CVRD e a Nippon Amazon Aluminum Corporation (Naac), um consórcio de empresas japonesas que participou com $49 \%$ do empreendimento, cabendo o restante à CVRD. E, para a produção da alumina, criou-se a Alumina do Norte do Brasil S. A. (Alunorte). 


\section{PGC: a concentração espacial \\ da política de incentivos fiscais e creditícios}

O Governo, ao assumir responsabilidades com obras de infra-estrutura, tais como a construção da Usina Hidrelétrica de Tucuruí - à época orçada em US\$ 2,1 bilhões e cujos custos finais alcançaram 7,5 bilhões - assim como os encargos relativos à linha de transmissão de energia da hidrelétrica até Barcarena (PA), a infra-estrutura viária, a portuária e as company towns necessárias aos empreendimentos, depara-se com dificuldade de financiá-las. Como o Governo Federal tinha necessidade de agilizar a instalação e o início da operação dos projetos mínerometalúrgicos, criou, em 1980, o Programa Grande Carajás (PGC). Uma tentativa de coordenar a execução de projetos já existentes na área (especialmente o Projeto Ferro Carajás, a Albras, a Alunorte, a Alumar e a Usina de Tucuruí) e de concentrar ainda mais os recursos estatais e os oriundos de incentivos fiscais e creditícios.

\section{A implantação de fábricas de aluminio na região}

Assim, no escopo do PGC, implantaram-se na região empresas voltadas à produção de alumina e alumínio primário. A Albras instalou-se no município paraense de Barcarena, iniciando sua operação em 1985. Nas negociações das condições de sua instalação, o Governo Federal concedeu à empresa subsídio no preço da energia elétrica. Vigorando entre 1985 e junho de 2004, tal concessão significou, segundo a Eletronorte, subsídios superiores a US\$ 1 bilhão.

Paralelamente às negociações que envolveram a criação da Albras, a Alcoa iniciou articulações também voltadas à produção de alumínio em São Luís (MA) e à formação, sob a sua coordenação, do Consórcio de Alumínio do Maranhão (Alumar). As obras para a sua instalação foram iniciadas em 1980 e sua produção, em 1984, já era comercializada.

No que se refere à instalação da Alunorte, ela enfrentou atrasos. Em 1987, a Naac, parceira da CVRD no negócio, decidiu não mais investir na Alunorte e suas obras foram, então, totalmente paralisadas. A conclusão das obras da Alunorte só ocorreu em 1995, hiato de tempo no qual o suprimento de alumina para a operação da Albras foi garantido pela importação daquele insumo.

\section{A exploração das minas da Serva dos Carajás}

Também foi no âmbito do PGC que se implementou, no sudeste paraense, atualmente município de Parauapebas, a extração do minério de ferro da Serra dos Carajás. Projeto cuja condução havia sido assumida, em 1977, pela CVRD. Para tanto, montou-se uma gigantesca estrutura envolvendo, além da company town na Serra dos Carajás, um sistema que abarca minas, instalações de beneficiamento e um pátio de estocagem, as instalações portuárias e a Estrada de Ferro Carajás, cujos 890 quilômetros de extensão interligam a Serra dos Carajás ao terminal marítimo da Ponta da Madeira, em São Luís (MA). Este sistema começou a operar em 1985. A mercantilização de minério de ferro atingiu 69,5 milhões de toneladas, em 2004, representando vendas de US\$ 1,32 bilhão. 
No bojo dos investimentos voltados à extração do minério de ferro de Carajás, ganhou também viabilidade econômica a exploração das jazidas de manganês do Igarapé do Azul, ainda em Carajás, de forma que, em finais de 1985, a CVRD iniciou a lavra daquela mina.

Em 2002, a CVRD instalou uma usina de pelotização do minério de ferro, em São Luís, que envolveu investimentos de US\$ 400 milhões. Ela tem por finalidade produzir sete milhões de toneladas de pelotas. Trata-se de uma planta industrial que adequará parcela $(10 \%)$ do minério de ferro de Carajás às exigências de segmentos da indústria siderúrgica.

A provável instalação, em São Luís, de uma aciaria para a produção anual de três milhões de toneladas de placas de aço em parceria com compradores chineses do minério de ferro de Carajás e a implantação, em Marabá, em sociedade com a Nucor, uma das maiores siderúrgicas dos Estados Unidos, de uma usina destinada à produção de $380 \mathrm{mil} \mathrm{t} / \mathrm{ano}$ de ferro gusa são parte da estratégia da mineradora de criar joint ventures com consumidores de minério de ferro para instalação de novos projetos. Deste modo, a CVRD efetiva alianças que objetivam, principalmente, consolidar e ampliar fatias de mercado, assim como esvaziar possíveis pretensões de esses consumidores migrarem para outros fornecedores de minério.

\section{Empresas sidero-metalúrgicas impulsionadas pelo PGC}

O PGC também incentivou, na sua área de abrangência, a instalação de empresas que se dedicassem à produção de ferro-gusa, ferroligas e silício metálico, chegando a autorizar a concessão de benefícios para a implantação de 22 empresas sídero-metalúrgicas.

A Camargo Corrêa Metais (CCM) também foi uma das empresas cuja previsão de operação pelo $\mathrm{PGC}$ se concretizou. A origem do seu capital vincula-se a incentivos fiscais concedidos, no âmbito do PGC, à Construtora Camargo Corrêa, que participou da construção da Hidrelétrica de Tucuruí. A CCM dedica-se à produção de silício metálico e localiza-se a $5 \mathrm{~km}$ da Usina de Tucuruí, no município paraense de Breu Branco.

Das empresas dedicadas à produção do ferro-gusa, instalaram-se e já iniciaram as obras de seus alto-fornos quinze siderúrgicas. Para sua instalação, a maioria dessas pequenas siderúrgicas contou com inúmeros favores estatais. $\mathrm{Na}$ composição dos seus capitais, os recursos oriundos do Fundo de Investimento da Amazônia (Finam) e do Fundo de Investimento do Nordeste (Finor) foram extremamente relevantes, em alguns casos representam até 75\% dos capitais investidos (Monteiro, 1998, p. 94).

Todas produzem tão-somente ferro-gusa, são por isso denominadas produtoras independentes, utilizando o carvão vegetal como o seu principal insumo. O carvão vegetal, oriundo quase que exclusivamente da floresta primária, é proveniente de lenha de desmatamentos ou é produzido tendo por base resíduos de madeira beneficiada por serrarias que também recorrem à floresta primária (Monteiro, 1998, p. 133). 
Durante as últimas duas décadas houve uma produção crescente de ferrogusa na região, que em 2004 atingiu 4,8 milhões de toneladas. Com a instalação, já confirmada, de novos alto-fornos na região, a produção continuará a ser ampliada. Isso implica também a ampliação do consumo de carvão vegetal, que já não é nem um pouco desprezível, são pelo menos cinco milhões de toneladas de carvão. Uma demanda que amplia a pressão pelo desmatamento de novas áreas, em especial com a elevação do preço do ferro gusa registrado em 2004.

\section{O fim da centralização autoritária}

O poder de centralização autoritária dos governos militares foi sendo corroído no decorrer da década de 1980, um processo que teve como corolário o fim desses governos, em 1985, e a promulgação da Constituição de 1988. Alteraram-se, assim, importantes mecanismos de mediação entre os interesses de diversos grupos no interior da sociedade, metamorfosearam-se as relações entre estados e União, um processo que teve desdobramentos diversos e significativos sobre a condução da política de valorização dos recursos minerais da Amazônia. O PGC é esvaziado para, em seguida, ser extinto. A Sudam e os diversos outros órgãos da burocracia federal que tiveram papel de destaque no aporte estatal para a implantação regional de empresas mínero-metalúrgicas têm a sua importância reduzida e parcela do sistema de renúncia fiscal que era executado no âmbito do PGC foi extinta. Entretanto, instrumentos importantes na consecução das políticas dos militares, como alocação direta de fundos públicos para a constituição de capitais de empresas, por intermédio do Finam e do Finor, e a concessão de isenção de IR foram mantidos.

Desenhou-se, assim, no final da década de 1980, um cenário no qual as políticas públicas voltadas à valorização dos recursos minerais da região são marcadas pela substancial redução da capacidade do Governo Federal de coordenar, centralizar e direcionar grandes financiamentos ou mesmo investimentos diretos em empresas mínero-metalúrgicas e em infra-estrutura de suporte a elas. O que, entrementes, não implicou, necessariamente, a extinção das políticas de renúncia fiscal ou de financiamentos, oriundos de fundos públicos a elas destinados.

\section{A expansão da exploração industrial do ouro nos anos de 1980 e 1990 do século XX}

No período em que se assistiu à corrosão da base de sustentação do regime militar e sua queda, houve também grande elevação no preço do ouro no mercado mundial. Isto impulsionou a expansão da valorização do ouro na Amazônia, uma dinâmica que implicou choques entre empresas mineradoras e garimpeiros em diversas áreas da região. Delas destaca-se aquela na qual se instalou a Mineração Novo Astro (MNA), que, em 1982, adquiriu direitos minerários de áreas de garimpagem conhecidas como garimpo Mutun e Lourenço, no município de Calçoene (AP). A partir daí, a empresa iniciou um processo de expulsão de cerca de 1.500 garimpeiros. 


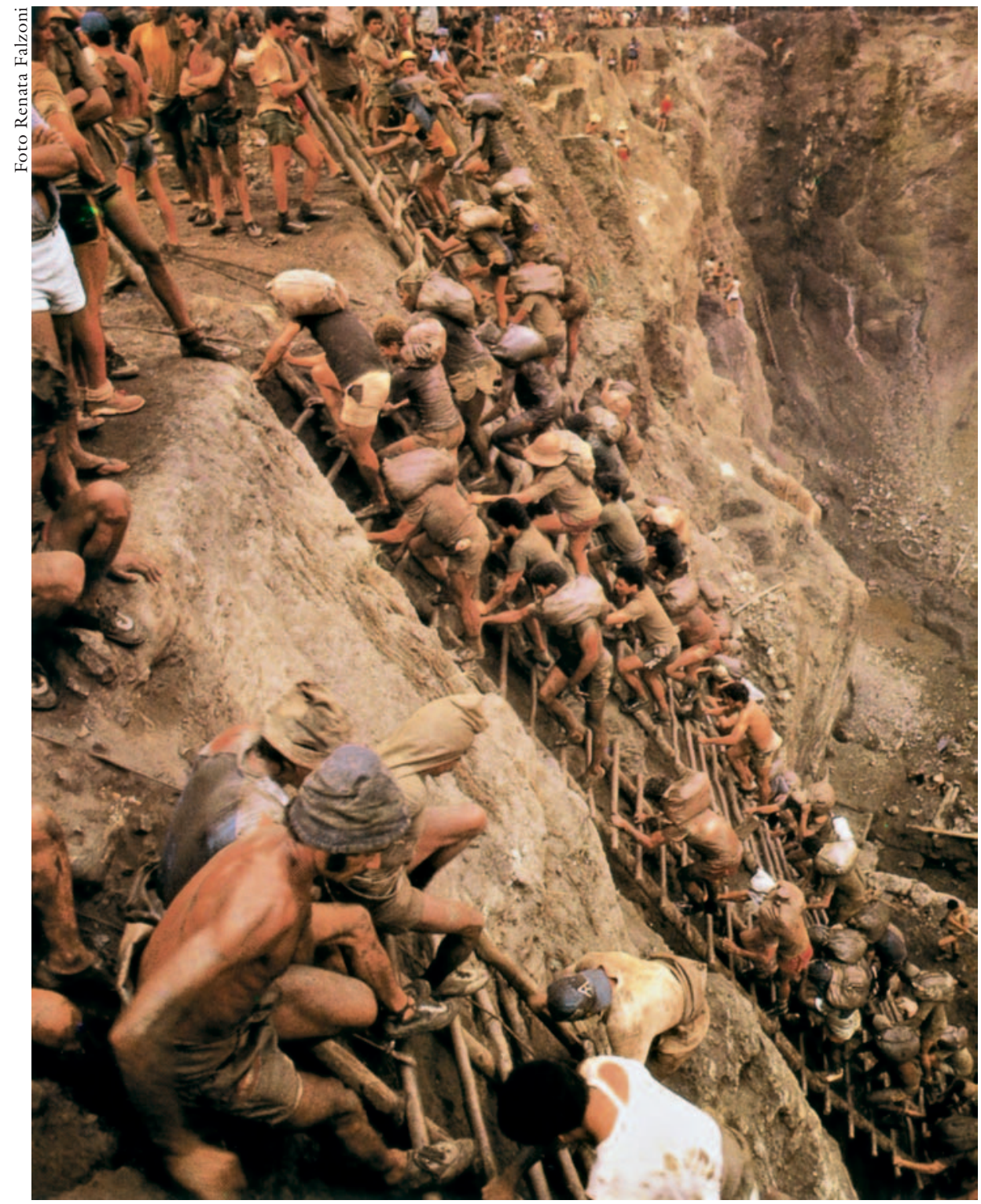

Trabalbadores na mina de ouro de Serra Pelada, Pará.

Em 1995, a MNA encerrou suas atividades. Apesar das muitas evidências em relação à enorme degradação ambiental ainda presente na área lavrada, a empresa obteve da Coordenadoria Especial de Meio Ambiente do Amapá (Cema) a aprovação de seu relatório final de recuperação das áreas degradadas. Diante do que a empresa transferiu seus direitos minerários para a recém-criada Cooperativa de Mineração dos Garimpeiros do Lourenço (Coogal). Na área, o que se encontra, hoje, é a prática da garimpagem conjugada a um quadro de degradação ambiental e social.

Em meados da década de 1980, duas novas empresas passaram a dedicar-se à exploração do ouro no Amapá e teve também início a extração do ouro da mina do igarapé Bahia, no Pará. 
Uma dessas empresas foi a Mineração Yukio Yoshidome S. A. (MYYSA), que se instalou às proximidades da MNA. A MYYSA entrou em funcionamento em 1985 e em 1992 encerrou suas atividades. As áreas degradadas pela mineração não foram recuperadas e atualmente se encontram ocupadas por garimpeiros.

Outra empresa dedicada à exploração industrial de ouro a entrar em operação, no Amapá, foi a Mineração Água Boa que iniciou, em 1992, a exploração da mina localizada no município de Mazagão (AP), às margens do Igarapé Santa Maria. Ela funcionou por cinco anos e quando encerrou as atividades não recuperou as áreas degradadas, deixando duas enormes cavas em cada uma das margens do Igarapé.

$\mathrm{Na}$ década de 1990, a produção industrial de ouro passou a ser regionalmente incrementada pela exploração das minas do Igarapé Bahia pela CVRD. A mina situava-se nas áreas da CVRD, no município de Parauapebas. Em 1990, iniciou a mercantilização do ouro, cuja extração, a partir de 1995, ultrapassou o volume anual de dez mil toneladas. Em 2002, todavia, a mina já estava exaurida.

\section{Reformas no Estado \\ e novas dinâmicas para a valorização mineral}

Com a eleição de Fernando Collor à presidência da República e, posteriormente, com a de Fernando Henrique Cardoso, consolidaram-se alterações em aspectos relevantes da forma de atuação, do sentido e das funções da intervenção estatal. No bojo de tais mudanças, incluem-se a diminuição de barreiras alfandegárias, a redução da tributação incidente sobre exportações e a redução da participação estatal na economia, por via, por exemplo, de privatizações de empresas estatais, como veio a acontecer com a CVRD.

Houve também mudança na legislação federal relacionada aos incentivos fiscais vinculados ao IR, extinguindo, a partir de 1997, a possibilidade de novas concessões de isenção de IR e, no caso de redução daquele imposto, estabeleceram-se percentuais menores dos que até então podiam ser concedidos. Mantiveram-se, entretanto, os benefícios já concedidos.

Mudanças na legislação ambiental, iniciadas no fim do regime militar, incorporadas à Constituição de 1988 e a afirmação crescente de uma legislação mais rigorosa também tiveram repercussões sobre os parâmetros que envolvem a valorização dos recursos minerais, uma vez que ganharam obrigatoriedade a realização de estudo de impacto e o licenciamento ambiental prévios e a recomposição do meio ambiente degradado pela mineração. Nesse escopo de ampliação da legislação ambiental, em 1998, foi promulgada a Lei de Crimes ambientais, que determinou a passagem da questão de danos ambientais da esfera administrativa para a esfera criminal.

Foi no âmbito dessa mudança que a Icomi se apressou em encerrar suas atividades e, em 1997, antes, portanto, de entrar em vigência a Lei de Crimes 
Ambientais e do final do prazo estabelecido no contrato de arrendamento das minas na Serra do Navio, ela declarou exauridas as reservas, após ter extraído 34 milhões de toneladas de minério de manganês. Entrementes, durante a tentativa de transferência da área industrial e portuária no município de Santana (AP) para a empresa Champion Papel e Celulose, constatou-se a contaminação das águas superficiais e de lençóis freáticos por arsênio e manganês. Dano ambiental este atribuído à deposição inadequada de resíduos originados nos processos tanto de pelotização quanto de sinterização da fração fina do minério de manganês (JPE, 1998).

Foi um período no qual também se alteram, no âmbito do Governo Federal, as concepções em relação às formas de se impulsionar o desenvolvimento regional. Nas décadas passadas, de uma forma ou de outra, a noção predominante era a de que a modernização da região vinculava-se ao estabelecimento de pólos de desenvolvimento; esta noção perdeu espaço para a concepção de que o fundamental para o desenvolvimento regional é o estabelecimento de "eixos estruturadores de integração nacional e internacional" (Brasil, 1997b, p. 17), concebidos como alternativa para articular diferentes regiões entre si. Esses eixos assumem a forma concreta de vias de transporte de longa distância que possibilitariam, segundo o Governo Federal, "acesso a mercados e melhorar a capacidade competitiva dos sistemas econômicos regionais" (Brasil, 1997b, p. 17). Em relação à mínero-metalurgia, o discurso do Governo Federal passa a indicar que ela poderia contribuir com o desenvolvimento regional, maximizando a utilização das vias de transporte existentes e as a serem criadas, bem como a partir da "geração de cadeias de integração produtiva" (Brasil, 1997a, p. 106).

Foi naquele contexto, também, que se aprovou a emenda constitucional no 6, que retirou o impedimento, até então existente, de o capital estrangeiro participar majoritariamente nos capitais de empresas de mineração. Mudança que permitiu, por exemplo, à norueguesa Elkem adquirir os direitos de lavra do minério de cromo no município de Mazagão (AP) e passar a dirigir a atividade por meio de sua subsidiária, a Mineração Vila Nova.

Tal mudança constitucional permitiu que a Rio Capim Caulim S. A. - uma empresa que pertencia ao Grupo Mendes Júnior, e que, em 1994, havia iniciado as obras tendo em vista a valorização de minas de caulim, às margens do rio Capim, no município de Ipixuna do Pará - fosse adquirida pela francesa Imerys, uma das maiores empresas mundiais de caulim, passando a denominar-se Imerys Rio Capim Caulim. Desde 1996, quando ocorreu o primeiro embarque de minério, a mercantilização do caulim tem se ampliado anualmente e a empresa pretende expandi-la até 1,2 milhão de t/ano, limite operacional do mineroduto que liga a mina às instalações de beneficiamento em Barcarena (PA).

No município de Ipixuna também se instalou a Pará Pigmentos S. A. (PPSA). Em 1996, a PPSA iniciou a lavra do caulim, que, depois de lavrado, é transportado para a usina de tratamento, de onde, já beneficiado, é bombeado, na forma de 
polpa, por um mineroduto com $180 \mathrm{~km}$ de extensão, até atingir as instalações da empresa em Barcarena, onde é secado e embarcado através de terminal portuário da própria empresa. Como as demais empresas que se dedicam à valorização do caulim na Amazônia, a PPSA pretende alcançar o volume de um milhão de t/ ano, limite para o qual foi projetado o seu mineroduto.

\section{As tensões no governo Lula e a manutenção de lógicas de valorização de minerais na Amazônia}

O documento que, em tese, deve dirigir a Política Nacional de Desenvolvimento Regional do governo do presidente Lula da Silva indica que um dos principais objetivos das ações do Governo Federal no que tange às políticas de desenvolvimento regional é o de "explorar, com afinco, os potenciais endógenos da magnificamente diversa base regional de desenvolvimento, em conformidade com os fundamentos sociais atuais de uma produção mais diversificada e sofisticada, mais portadora de valores sociais regionalmente constituídos" (Brasil, 2003a, p. 12). Trata-se de uma referência que explicita o apoio, como mecanismo de desenvolvimento regional, àqueles agentes que têm a sua competitividade baseada em vantagens competitivas (Dosi et al., 1990) e não àqueles agentes cuja estratégia de competitividade apóia-se na utilização tão-somente de vantagens comparativas oriundas dos baixos custos para se acessar recursos naturais. Este mesmo fundamento, em linhas gerais, também está presente no documento Plano Amazônia Sustentável (Brasil, 2004, p. 60).

Todavia, em termos de ações concretas, a atuação do Governo Federal para a Amazônia não tem se pautado, fundamentalmente, no que está exposto naqueles documentos, pois uma análise das ações do Governo para a Amazônia indica que a lógica de sua atuação vincula-se, em grande medida, a uma estratégia expressa no documento Plano Plurianual 2004-2007 (Brasil, 2003b) e que comporta ações que reforçam as lógicas, vigentes nos períodos anteriores, de relacionamento entre o poder público e as empresas responsáveis pela mercantilização de bens de origem mineral.

O Plano Plurianual Brasil tem como ponto de referência uma análise de que o desenvolvimento econômico do país está bloqueado pela existência de restrições que produzem vulnerabilidade externa e interna. A primeira delas vinculada à baixa capacidade de geração de divisas na balança comercial e de atração de capitais produtivos. Essa reduzida capacidade de geração de divisas tem tornado o Brasil altamente dependente de capitais para fechar suas contas com o resto do mundo. Nesses termos, a superação da vulnerabilidade externa requer que seja dada máxima prioridade para a elevação do saldo da balança comercial, o que implica dispensar tratamento privilegiado aos agentes econômicos, como as empresas mínero-metalúrgicas, cujas mercadorias exportadas têm baixíssimo coeficiente de importação, do que deriva um resultado líquido maior nas contas correntes externas. 


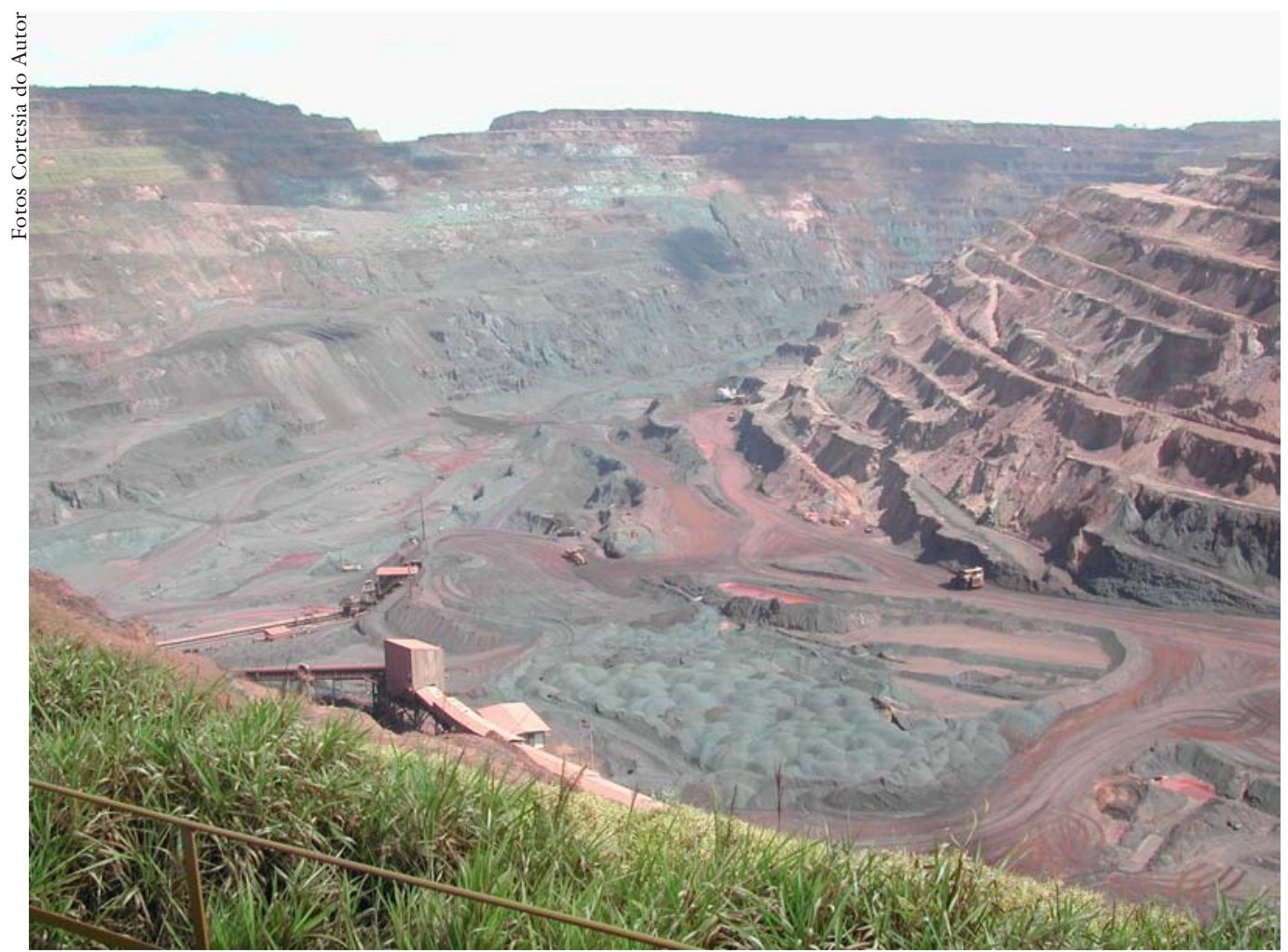

Mina de minério de ferro, Carajás, Pará.

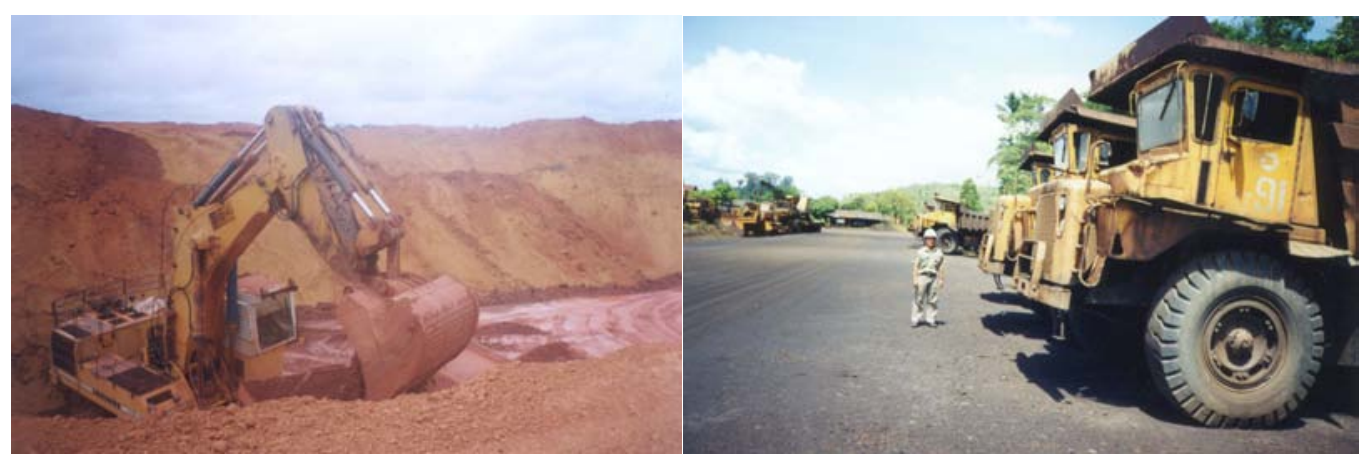

Escavadeira na região do rio Trombetas, PA. Caminhões na Serra do Navio.

Essa postura do Governo é manifesta na presença do próprio presidente da República na inauguração na terceira linha de produção da Alunorte, que permitiu incrementar o volume exportado pela empresa de 730 mil toneladas de alumina para 1,4 milhão de toneladas por ano. Em 2004, tais exportações significaram vendas de US\$ 307 milhões, presença que se repetiu na inauguração, em 2004, de projeto da CVRD, na região de Carajás, destinado à valorização de minério cobre na mina do Sossego que, durante as próximas duas décadas, será responsável pela mercantilização anual de 140 mil toneladas de cobre.

A política do Governo Federal de priorizar a ampliação de superávits na balança comercial tem desdobramentos concretos sobre os processos de desenvolvimento em curso na Amazônia, pois tais prioridades convergem com a ação 
e redundam em práticas que fortalecem agentes econômicos que se valem das vantagens comparativas derivadas do baixo custo, em termos presentes, do uso dos recursos naturais da região, ou seja, a valorização de minério de ferro, de bauxita, de cobre, de alumina, de alumínio, do ferro-gusa e não com o estabelecimento de políticas que sejam capazes de explorar os "potenciais endógenos" e impulsionar "uma produção mais diversificada e sofisticada".

\section{Valorização de recursos minerais e desenvolvimento local}

Os desdobramentos decorrentes da mercantilização de recursos minerais em termos regionais, apesar de envolverem produção de mercadorias bastante diversas, valorizadas por empresas que foram instaladas em momentos históricos distintos, guardam importantes e decisivas singularidades e contam com lógicas e características comuns no que tange a repercussões em relação aos processos de desenvolvimento regional. Nestes termos, a análise das dinâmicas gerais derivadas das atividades voltadas à valorização de minerais da região facilita, sobretudo, a compreensão sobre a limitada capacidade de impulsionarem processos de desenvolvimento local.

Essa limitação de a mínero-metalurgia impulsionar dinâmicas de desenvolvimento amplas e socialmente enraizadas torna-se mais clara quando se levam em conta as novas abordagens sobre processo de desenvolvimento fundamentadas em interpretações das trajetórias de inovação tecnológica (Dosi et al., 1988; Freeman, 1994) e em novas abordagens acerca da organização institucional e do caráter endógeno de processos de desenvolvimento duradouros (Romer, 1994; Krugman, 1995 e Arthur, 2000) que apontam a necessidade de se considerar o papel assumido pelo capital social (Coleman, 1990) e pelas especificidades sociais, institucionais, culturais e ecológicas como elementos determinantes para se implantar processo de desenvolvimento local. Trata-se assim da capacidade de se estabelecer regionalmente vantagens competitivas que seriam decorrentes de uma ambiência historicamente construída (Dosi et al., 1988) e não da simples utilização de vantagens comparativas cujos supostos teóricos derivam de modelos vinculados à economia neoclássica e embasadas na suposição de que a eficiente alocação de fatores de produção em uma região (teorema de Heckscher-Ohlin-Samuelson) ofereceria condições para seu desenvolvimento mediante a intensificação do comércio.

A lógica que impulsionou a mínero-metalurgia na região é a de assegurar sua viabilidade econômica tendo por base a garantia da utilização de vantagens comparativas decorrentes da possibilidade de acessar recursos e serviços ambientais a baixo custo, o que não a vincula à existência ou à necessidade de ela se integrar ou interagir com arranjos produtivos locais nos quais, ao lado da existência de recursos naturais, o capital humano e o social sejam elementos determinantes para o estabelecimento de vantagens competitivas que permitam processos de desenvolvimento socialmente enraizados. 
A possibilidade de se acessar recursos naturais a baixo custo foi determinante para que houvesse uma drástica alteração nas exportações da Amazônia oriental, o Pará, por exemplo, cujo montante das exportações, em 1976, totalizava US\$ 109,83 milhões, e foi multiplicado por 34 , incremento vinculado às exportações de produtos mínero-metalúrgicos; estes alcançaram, em 2004, 77\% do valor total das exportações paraenses que, naquele ano, somaram US\$ 3,8 bilhões. Todavia, a literatura especializada corrobora que se deve levar em conta que a implantação de novas atividades econômicas pode elevar os níveis de produção de uma região ou de uma localidade sem que, entretanto, ocorra um processo de desenvolvimento econômico e social. Este parece ser o caso das atividades mínerometalúrgicas, pois não foram capazes de impulsionar, na Amazônia oriental brasileira, processos de desenvolvimento de base local, endógenos, socialmente enraizados, por isso, sustentáveis. Portanto, em que pese ao gigantismo dos volumes e cifras movimentados como decorrência da extração, do beneficiamento e da transformação industrial de recursos minerais; à rápida elevação das taxas de crescimento econômico da região; ao favorecimento pelo aparato estatal por meio de concessões de subsídios e de inúmeras facilidades creditícias e fiscais; e à aplicação de vultosos recursos - oriundos de fundos públicos - em infra-estrutura ou mesmo diretamente na estruturação de empresas, a mínero-metalurgia não deve ser incluída dentre as atividades que impulsionam dinâmicas de desenvolvimento endógeno e sustentáveis na região.

\section{Dificuldades de enraizar processos de desenvolvimento}

Durante meio século, em diversos momentos, em torno das atividades mínero-metalúrgicas, foram construídas expectativas de que, como decorrência do atendimento de demandas globais de mercadorias minerais, abrir-se-ia a possibilidade para o estabelecimento de processos impulsionadores do desenvolvimento regional por meio do surgimento de uma vasta rede de relações sociais, mercantis e não mercantis, tendo como elemento estruturador a mínero-metalurgia.

A expectativa, recorrentemente acalentada, era de que a mínero-metalurgia produziria rápidos efeitos de encadeamento industrial. Entretanto, ela não foi capaz de impulsionar o surgimento da propalada rede de relações como fruto de encadeamentos "para frente e para trás" das atividades de mineração e síderometalurgia.

As dificuldades de a mínero-metalurgia impulsionar processos de desenvolvimento de base local, todavia, não residem fundamentalmente na limitada capacidade de estabelecer encadeamento produtivo. Uma das razões encontra-se no fato de estas atividades serem profundamente dependentes de dinâmicas extra-regionais que, por sua vez, determinam os padrões tecnológicos, de inovação e de organização dentro dos quais as empresas mínero-metalúrgicas têm de operar, o que as distanciam da articulação ou mesmo da construção de arranjos produtivos de base local. 


\section{Politicas tributárias}

\section{desarticuladas de estratégias de desenvolvimento local}

Outro aspecto que poderia ter repercussões para o desenvolvimento regional seria a arrecadação tributária, lato sensu, decorrente da valorização de recursos minerais.

A possibilidade de a sociedade, por meio das estruturas estatais, capturar parte do valor gerado como decorrência da mercantilização de recursos minerais regionais efetiva-se por meio de tributação que incide tanto sobre a extração e a comercialização, quanto sobre o lucro auferido pelas empresas. Contudo, o volume da receita tributária decorrente dessas atividades é pouco significativo se comparado ao faturamento e ao lucro dessas empresas, o que decorre de políticas que, mesmo elaboradas e implementadas em momentos históricos distintos, tiveram como desdobramento comum a sistemática renúncia fiscal no que concerne às atividades mínero-metalúrgicas.

Trata-se de políticas fiscais que se articulam com interesses de capitais presentes em regiões mais desenvolvidas que, por meio de relações hierarquizadas e de apropriação desigual do poder político, impulsionam políticas públicas que representam seus interesses. No caso da mínero-metalurgia, a capacidade de ela gerar grande volume de exportações de forma regular permite a obtenção de saldos favoráveis na balança comercial, o que atende aos interesses de importantes segmentos de regiões mais desenvolvidas. Contudo, essas políticas não necessariamente se coadunam com o reforço a dinâmicas que favoreçam o desenvolvimento em termos regionais e locais. Nesse contexto, favores fiscais são estabelecidos muito mais em decorrência de interesses extra-regionais do que, efetivamente, como políticas públicas articuladas e voltadas para o desenvolvimento da região.

O principal desses favores fiscais relaciona-se com a isenção ou com a redução do imposto sobre o lucro por período de até dez anos. Na Amazônia oriental brasileira, quase todos os empreendimentos mínero-metalúrgicos contaram ou contam com esse tipo de favor fiscal.

As políticas tributárias também evidenciam poder limitado de a sociedade regional valer-se das especificidades que envolvem a valorização de recursos minerais, pois o fato de as atividades de lavra, diferentemente de outras atividades econômicas, terem de, obrigatoriamente, ser desenvolvidas na área da ocorrência mineral - o que se costuma chamar rigidez locacional - poderia resultar no estabelecimento de dinâmicas sociais que possibilitassem a elevação da tributação decorrente da valorização dessas reservas, especialmente a ampliação da Compensação Financeira pela Exploração de Recursos Minerais - CFEM (royalties) relativa à valorização da hematita e da bauxita que poderia comportar dilatação, sem comprometer a competitividade destes mercados, em decorrência das características destas minas e dos mercados mundiais (Monteiro, 2004). Todavia, não é isto que ocorre. 
Se, por um lado, a rigidez locacional que caracteriza a exploração das minas não é utilizada de forma eficaz por parte dos estados nacionais e membros da federação para ampliar a tributação, por outro, a flexibilidade que as empresas possuem em relação às possibilidades de localização das plantas industriais nas quais se realizam etapas posteriores da transformação de bens minerais é utilizada de forma hábil por elas para que estados nacionais e membros da federação estabeleçam políticas fiscais e tributárias que lhes sejam favoráveis. Há, de tal forma, assimetrias nas negociações que envolvem a rigidez locacional da extração e beneficiamento primário e a flexibilidade das etapas posteriores de processamento dos minérios.

Foram estabelecidas relações que favorecem as empresas que têm seus interesses articulados com a valorização de recursos minerais da região, o que se efetiva em detrimento de outros grupos sociais e de políticas indutoras de desenvolvimento local.

\section{Grande concentração de capitais e pouca difusão de tecnologias}

A mínero-metalurgia, em termos gerais, requer elevadíssima concentração de capitais. Alguns empreendimentos demandaram investimentos superiores a US\$ 1 bilhão, como no caso da exploração do ferro, em Carajás; da bauxita, na região do Trombetas; da produção da Alumina pela Alunorte; e da fabricação de alumínio primário pela Albras e pela Alumar. Todavia, o controle desses capitais é efetivado extra-regionalmente, não reforçando a região como local de decisão.

Essa grande concentração de capitais enseja, também, de forma quase que direta, concentração de renda, e não colabora para que se estenda a propriedade de meios de produção a segmentos mais amplos da sociedade. Trata-se, portanto, de dinâmicas que não se coadunam com processos de desenvolvimento de base local, pois estes requerem a ampliação da eqüidade social, intimamente associada à desconcentração da renda e da propriedade de meios de produção. Ademais, é muito elevada a composição orgânica desses capitais, ou seja, eles requerem grandes investimentos em maquinário e em infra-estrutura (capital fixo), quando comparados ao volume de recursos destinados à remuneração da força de trabalho (capital variável). Todavia, a maquinaria não é produzida na região e a tecnologia para a implantação da infra-estrutura também não é gestada regionalmente. Em ambos os casos são trazidas para a região na forma de pacotes tecnológicos fechados. Assim, a maneira pela qual maquinaria e infra-estrutura são incorporadas ao processo produtivo faz com que inexistam mecanismos significativos de difusão, para outras atividades existentes na região, da tecnologia incorporada tanto na maquinaria e nos processos de gestão quanto na infraestrutura que serve às empresas mínero-metalúrgicas.

\section{Limitada capacidade de interagir com a diversidade local}

A extração e a transformação industrial de minerais na Amazônia oriental brasileira, em função das características dos mercados, necessitam recorrer a pro- 
cedimentos industriais padronizados em termos globais, de forma que, por exemplo, a lavra da bauxita, sua transformação em alumina e posteriormente em alumínio primário; a lavra do minério de ferro, a pelotização deste minério, a produção de ferro-gusa e, no futuro próximo, do aço, utilizam sistemas industriais homogêneos, ou seja, são processos produtivos que replicam outros existentes no mundo. Essas atividades, ao demandarem processos produtivos desenvolvidos e implementados noutros contextos sociais, culturais e ecológicos, diante da própria fragilidade da organização da sociedade local, consolidam habitus e passam a ter dificuldade de interagir com a diversidade regional, pois, a partir desta diversidade, constituem-se em realidades e atores (índios, camponeses, empresários locais etc.) com os quais a mínero-metalurgia tem enorme dificuldade de interatuar e, com freqüência, assume uma postura conflitante e antagônica em relação a estes.

\section{Assimetrias no acesso e na mercantilização de inputs energéticos}

As atividades mínero-metalúrgicas demandam energia em níveis bastante diferenciados. Estas distinções entre os fluxos energéticos são derivadas das especificidades dos processos de valorização de cada recurso mineral. Assim, as atividades de extração e de beneficiamento primário demandam significativamente menos energia do que aquelas que envolvem a transformação industrial do mineral. As etapas que envolvem a transformação metalúrgica ou siderúrgica de mercadorias minerais, quando comparadas com as demais atividades voltadas à valorização regional de recursos minerais, aparecem como amplamente dependentes de inputs energéticos.

Em face dessa diferenciação, as empresas que atuam na extração e beneficiamento primário de minerais não têm no suprimento energético elementos relevantes de suas estratégias de competitividade. Já as estratégias daquelas empresas cuja atividade demanda significativamente mais energia voltam-se para o desenvolvimento de uma série de ações que lhes permitam o acesso a inputs energéticos com os menores preços possíveis.

Assim, para a instalação de unidades industriais destinadas à transformação industrial de bens minerais na região que efetivam a produção de alumínio primário, de silício metálico e de ferro-gusa foi decisiva a existência de um grande potencial hidrelétrico e de um grande volume de biomassa vegetal, possibilitando o acesso a inputs energéticos capazes de viabilizar aqueles processos industriais.

No caso do suprimento de energia elétrica, a mercantilização de serviço ambiental representado pelo potencial hidrelétrico regional requereu diversas mediações que envolveram o estado nacional e empresas de atuação global que, em última análise, transferiram para o primeiro custos de construção da usina hidrelétrica de Tucuruí e garantiram para si preços reduzidos para a aquisição de energia elétrica. De forma semelhante, foram estabelecidas relações sociais que viabilizam o fácil e barato acesso à biomassa originária da floresta primária para a produção de carvão vegetal utilizado como input energético no processo de 
valorização do ferro-gusa e do silício metálico. Trata-se de exemplos da assimetria que envolve diferenciações sociais no acesso e no uso de serviços ambientais.

Portanto, no caso da hidroeletricidade e da biomassa vegetal, foram edificadas relações que garantiram mecanismos para permitir que, com baixíssimos custos econômicos, vultosos recursos e serviços ambientais fossem convertidos em mercadorias. Processos para os quais foi decisiva a atuação do estado nacional. É uma lógica que permite que determinados segmentos sociais apropriemse de riqueza oriunda de fundos públicos e de vastíssimo patrimônio constituído de serviços ambientais como também que haja assimetrias entre empresas siderúrgicas e metalúrgicas e outros segmentos da sociedade no acesso e aquisição de inputs energéticos.

\section{A inobservância do princípio da prudência ambiental}

A valorização regional de recursos minerais patrocinou também práticas ambientalmente deletérias. Talvez o exemplo mais significativo desta situação advenha das constatações efetivadas após o fechamento das primeiras minas submetidas à exploração industrial no Amapá. Em todas é visível, sem grande esforço, um passivo ambiental seguramente muito significativo, embora ainda não dimensionado. Um passivo cuja face mais evidente é a não-recuperação das áreas degradadas pela mineração, como se constata nos locais onde atuaram a MNA, a MYYSA e a Mineração Água Boa ou mesmo em passivos ambientais mais difíceis de serem identificados, mas de implicações extremamente graves, como é o caso representado pela contaminação de lençóis freáticos por arsênio, na área do porto da Icomi, no município de Santana (AP). Este problema ambiental hoje é atribuído aos rejeitos produzidos pela usina de pelotização de minério de manganês da Icomi, implantada na década de 1970. Entretanto, na época de sua instalação, esta usina foi apresentada como fruto de "importantes pesquisas, desenvolvidas durante cerca de três anos nos laboratórios da empresa no Amapá e no Homer Research Laboratories, da Bethlehem Steel nos Estados Unidos" e reivindicada como um marco de um desafio vencido: "a instalação de equipamentos de alta tecnologia em plena Amazônia” (Icomi, 1975, p. 17). Neste caso específico, um processo produtivo que foi apresentado à sociedade e aceito como portador de alta tecnologia e como fruto de anos de pesquisa, décadas depois, revelou-se como uma "bomba de efeito retardado".

Fruto de lógica similar, insere-se o caso do assoreamento do lago Batata. Nos anos de 1990, quando a MRN já não lançava mais os rejeitos do beneficiamento da bauxita no lago, os responsáveis pelo problema argumentavam que a "ausência de tecnologia" e o "nível de consciência ecológica da época" (Planasa, 1994, p. 67) foram os responsáveis pelo procedimento adotado por uma década, do qual resultou um dano ambiental gravíssimo. Assim, na visão da MRN, como os avanços na tecnologia e na consciência ambiental só se efetivaram anos depois de o processo já ter se iniciado, aquelas práticas não poderiam, naquele momento, ser tomadas como agressões ao ambiente efetuadas por negligência ou dolo, 
pois não haviam sido social nem mesmo tecnologicamente estabelecidos parâmetros que as caracterizassem como tal.

Estes são alguns dos exemplos que indicam o quão comum é a constatação de que certos procedimentos que envolvem a valorização de recursos minerais podem representar gravíssimos problemas ambientais. Entretanto, no momento em que estão sendo colocados em prática tais procedimentos voltados à valorização de recursos minerais, a sociedade e mesmo os próprios responsáveis pelas atividades desconsideram o princípio da prudência ambiental.

\section{Pistas para articular a mínero-metalurgia com o desenvolvimento regional}

No Amapá, a exaustão das primeiras minas submetidas à exploração industrial na Amazônia tornou mais evidente algumas das contradições, que se expressam na capacidade limitada de a mínero-metalurgia impulsionar processos de desenvolvimento local. Tanto que naquele Estado é nítida a frustração em relação à colaboração das atividades minerais para o desenvolvimento da região (Porto, 2003). Uma frustração que toma formas concretas com a visão das "crateras", como as formadas na Serra do Navio; ou com a constatação de que das poucas sinalizações em direção à "verticalização" da produção mineral naquele estado só restam os alicerces.

Diante de razões geológicas, históricas, de mercado e logísticas, e de um saldo questionável, deve-se ampliar as reflexões acerca das condições sob as quais é possível converter os recursos minerais da região em vetores de desenvolvimento. Em especial porque a mínero-metalurgia, na primeira década deste século, será a atividade que realizará o maior volume de investimentos na Amazônia oriental brasileira.

Há que se considerar que se trata de agentes sociais e econômicos que têm sua trajetória marcada pelo reforço a um projeto de desenvolvimento regional assentado na concentração da renda, na homogeneização dos processos produtivos e na desvalorização do capital natural da região e cujos habitus os distanciam da possibilidade de estabelecerem redes de relações sociais, econômicas, políticas e ambientais que sejam impulsionadoras do desenvolvimento regional baseado na construção de arranjos produtivos locais capazes de alimentarem localmente dinâmicas de inovação que favoreçam o estabelecimento de processos produtivos cujo diferencial de competitividade não esteja baseado, tão-somente, na utilização, a baixo custo, de recursos e serviços ambientais da região.

Dessa forma, as ações do Governo Federal e de amplos segmentos da sociedade diante destas empresas mínero-metalúrgicas não podem ser interpretadas como neutras em relação aos desdobramentos dos processos de desenvolvimento em curso na Amazônia. Nestes termos, é necessária a criação de uma ambiência social que favoreça e possibilite um rígido controle ambiental das atividades mínero-metalúrgicas, buscando evitar a prática da transferência de custos priva- 
dos para a sociedade e, sobretudo, criando uma tensão que busque bloquear comportamentos oportunistas, no que se refere à externalização de custos e que induza a adoção de mecanismos de inovação para a garantia da competitividade.

No que se refere à questão fiscal e tributária, se, por um lado, a renúncia fiscal beneficia, em nome do esforço exportador e, em certos casos, estabelece a possibilidade de concorrência no mercado internacional de uma empresa mínerometalúrgica, por outro, esta renúncia fiscal, especialmente se levando em conta que os fundamentos de tais concessões são contratuais, pode se configurar como instrumento apto a induzir comportamentos de empresas mineradoras que impulsionem processos de desenvolvimento de caráter endógeno, tais como a cooperação técnica interempresas, o estabelecimento de mecanismos de difusão tecnológica, a formatação de cadeias de subcontratação que assumam formato que possam vir a favorecer o desenvolvimento local etc.

Outra possibilidade de articular a mínero-metalurgia com o desenvolvimento local é a de se ampliar, via tributação, lato sensu, a parte do valor criado pela mineração. A ampliação das alíquotas dos royalties, por exemplo, não comprometeria a competitividade internacional das commodities, uma vez que se encontram bem abaixo da média mundial (Monteiro, 2004). Poderiam ser recursos cuja destinação voltar-se-ia ao fortalecimento de processos de desenvolvimento fundamentados no estabelecimento de vantagens competitivas socialmente criadas e integradas ao uso sustentável da base natural da região.

Trata-se de uma possibilidade. Todavia, distante de ser uma realidade, uma vez que isto implica confronto com interesses econômicos, visões de mundo, com o tradicionalismo de diversas ordens e instituições etc., o que requer firmeza e clareza estratégica dos dirigentes políticos, a edificação de uma institucionalidade pública na Amazônia que seja permeável à pluralidade de forças que expressam a sua diversidade social e cultural, e, sobretudo, a ampla mobilização dos diversos segmentos sociais comprometidos com um novo tipo de desenvolvimento regional.

\section{Bibliografia}

ARTHUR, W. B. Increasing Returns and Path Dependence in the Economy. Michigan, The University of Michigan Press, 2000.

BRASIL. Ministério da Integração Nacional, Ministério do Meio Ambiente. Plano Amazônia Sustentável. Brasília, 2004.

. Ministério da Integração Nacional. Política Nacional de Desenvolvimento Regional. Proposta para discussão. Brasília, 2003a.

. Ministério do Planejamento e Orçamento e Gestão. Plano Plurianual 20042007, Brasília, 2003b.

. Ministério do Planejamento e Orçamento. Projeto de desenvolvimento integrado da região norte. Brasília, Universa, 1997a. 
. Indicações para uma nova estratégia de desenvolvimento regional. Brasília, Universa, 1997b.

COLEMAN, J. Foundations of Social Theory. Cambridge, The Belknap Press of Harvard University Press, 1990.

CHANDLER JR., Alfred D. The Visible Hand. The Managerial Revolution in American Business. Cambridge, Harvard University Press, 1977.

DOSI et al. Technical Change and Economic Theory. London, Pinter Publishers, 1988.

FREEMAN, C. “The Economics of Technical Change”. Cambridge Journal of Economics, vol. 18, n. 1. 1994.

ICOMI. O manganês do Amapá 1975/76. Macapá, ICOMI, 1975.

JPE. Disposição final dos resíduos da usina de pelotização. Santana, Icomi, 1998.

KRUGMAN, P. Development, Geography, and Economic Theory. Cambridge, The MIT Press. 1995.

MONTEIRO, Maurílio. A siderurgia e carvoejamento na Amazônia. Drenagem energético-material e pauperização regional. Belém, Naea/ UFPA, 1998.

. Mineração, tributação e desenvolvimento regional. Belém, Naea/ UFPA, 2004. Paper do Naea.

OLIVEIRA, Francisco de. “A reconquista da Amazônia”. Em D’INCAO, Maria Ângela e SILVEIRA, Isolda Maciel (orgs.). A Amazônia e a crise de modernização. Belém, Museu Paraense Emílio Goeldi, 1994, pp. 185-96.

PLANASA. Projeto de redução de imposto de renda para bauxita lavada. Belém, Planasa, 1994.

PORTO, J. L. R. Amapá: principais transformações econômicas e institucionais - 1943 a 2000. Macapá, Secretaria de Estado de Ciência e Tecnologia do Amapá - Setec, 2003.

ROCHA, Ariadne da Silva Nodari et al. A política mineral na constituiçãa de 1967. Rio de Janeiro, MCT/CNPq/ Cetem, 1987 (Série Estudos e Documentos).

ROMER, P. M. “The Origins of Endogenous Growth”. Journal of Economic Perspectives, vol. 8, n. 1, 1994, pp. 3-22.

RESUMO - A IMPLANTAÇÃO na Amazônia oriental brasileira, nas últimas cinco décadas, de empresas voltadas à extração e à transformação industrial de minerais acalentou, recorrentemente, em diversos e amplos segmentos sociais, expectativas de rápida industrialização regional como derivação da utilização de "vantagens comparativas" decorrentes do atendimento de demandas globais de mercadorias minerais. Todavia, as atividades mínero-metalúrgicas tiveram enormes limitações em impulsionar dinâmicas de desenvolvimento amplas e socialmente enraizadas, o que resulta, em grande medida, das trajetórias e dinâmicas de inovação tecnológica a que são vinculadas, da ambiência institucional na qual estão inseridas e da pouca importância que é requerida das especificidades sociais, culturais e ecológicas locais para garantir a competitividade da valorização pouco qualificada de recursos minerais da região. 
ABSRACT - THE ESTABLISHMENT of mineral extraction and mineral transformation industries in the Western Brazilian Amazon in the last five decades created recurrent and widespread expectations of a fast regional industrialization resulting from "comparative advantages" brought by the fulfillment of the world demand for mineral commodities. Mineral and metallurgic activities have proven nevertheless to have a very limited capacity to foster broad and socially rooted development dynamics. This phenomenon may be partially explained by the particular dynamics of technological innovation in those industries, by the institutional environment in which they are embedded and finally by the secondary role played by the social, cultural and ecological characteristics of the region in order to guarantee a competitive valorization of the mineral resources of the Western Amazon.

Palavras-chave: Amazônia, Mineração, Metalurgia, Desenvolvimento Regional.

Keywords: Amazonia, Mining, Metallurgy, Regional Development.

Maurílio de Abreu Monteiro é doutor em desenvolvimento socioambiental, professor e pesquisador do Núcleo de Altos Estudos Amazônicos da Universidade Federal do Pará (Naea-UFPA). A elaboração deste texto contou com apoio financeiro do CNPq.

Texto recebido em 2 de fevereiro de 2005 e aceito para publicação em 26 de fevereiro de 2005 . 